\title{
The Association between Visceral Fat, Dietary Patterns, and Comorbidities
}

\author{
Louay Labban, Zeina Malek \\ Faculty of Pharmacy, Syrian Private University, Damascus, Syria \\ Email: drlouay@gmail.com
}

How to cite this paper: Labban, L. and Malek, Z. (2018) The Association between Visceral Fat, Dietary Patterns, and Comor bidities. Open Access Library Journal, 5: e4654.

https://doi.org/10.4236/oalib.1104654

Received: May 11, 2018

Accepted: July 10, 2018

Published: July 13, 2018

Copyright $\odot 2018$ by authors and Open Access Library Inc.

This work is licensed under the Creative Commons Attribution International License (CC BY 4.0).

http://creativecommons.org/licenses/by/4.0/

\section{(c) (i) Open Access}

\begin{abstract}
Visceral fat is technically the excess accumulation of intra-abdominal adipose tissue. This type of fat is stored further underneath the skin than subcutaneous fat and it's actually wrapped around major organs, including liver, pancreas and kidneys. Studies have shown that visceral fat plays a distinctive and potentially dangerous role affecting hormones function and it is also associated with increased risks of a number of health problems. Many indicators have been used to link visceral fats to chronic diseases including diabetes type 2, CVD, and arthritis. Anthropometric measurements, such as BMI, skinfold thickness, fat percentage, Waist Circumference, Hip Circumference and Waist/Hip Ratio indicating abdominal obesity. Dietary patterns also play a major role in overweight and obesity and in the amount of visceral fat accumulated in the body. The aim of the study was to find the association between visceral fat and chronic disease and also to identify the link between dietary patterns and chronic diseases. 61 males and 67 females participated in this study. Their anthropometric measurements were recorded together with their lipid profile and their energy intake and the number of servings of fruits, vegetables and dairy were also registered. The results have shown that females had higher BMI, waist and hip circumference, values of LDL, TG, TC and HDL than males and difference was statistically significant $(p<0.05)$. Waist/Hip ratio was higher in females but skinfold thickness was higher in males. Energy intake was almost similar in males $(2800 \mathrm{kcal})$ and females (2700 kcal) but females consumed more calories from $\mathrm{CHO}$ and fewer calories from protein and fat. They also consumed less fruits and dairy products. However, they consumed similar number of servings of vegetables. More females were diagnosed with chronic diseases such as diabetes, CVD, hypertension and arthritis comparing to their males counterpart.
\end{abstract}

\section{Subject Areas}

Diabetes and Endocrinology, Nutrition, Public Health 


\section{Keywords}

BMI, Visceral Fats, Waist Circumference, Waist to Hip Ratio, Diabetes, Hypertension, CVD

\section{Introduction}

The global health authorities consider obesity as a global epidemic which increases the rate of mortality due to its many comorbidities including coronary heart disease, hypertension and stroke, cancers, diabetes mellitus, gallbladder disease, dyslipidemias, osteoarthritis, and pulmonary diseases [1]. In order to determine the general obesity, Body mass index (BMI) can be used as a well-recognized index that can be a cardiovascular risk factor [2]. Visceral fat or central obesity can be measured by different parameters such as the waist circumference (WC), and waist-to-hip ratio (WHR). These measurements predict cardiovascular disease and all-cause mortality. While the International Diabetes Federation (IDF) and National Cholesterol Education Program Adult Treatment Panel III (NCEP ATP III) [3] recommended the use of waist circumference (WC), the WHO [4] recommended waist-to-hip ratio (WHR) as a measure of central obesity. Furthermore, it has been suggested that the predictive power of anthropometric indices is population-dependent, and varies across ethnic groups. Waist circumference and the waist-to-hip ratio are widely used as indicators of abdominal obesity in population studies. It is increasingly clear that the waist circumference may be a better reflection of the accumulation of or visceral fat than the waist-to-hip ratio, because of the postulated role of the visceral fat depot in health risks associated with obesity [5]. The waist-to-hip ratio is, however, a robust measure of risk in many population studies and it has been proposed that an increased waist-to-hip ratio may reflect both a relative abundance of abdominal fat (increased waist circumference) and a relative lack of gluteal muscle (decreased hip circumference) [6]. In a small study of Swedish men, it was observed that a high waist-to-hip ratio, after adjustment for age and body mass index (BMI), was associated with an increased visceral fat area and a decreased thigh muscle area [7].

While there are many studies in different parts of the world which have compared the relationship between these measures of central obesity and chronic diseases risk factors, there are no such reports in Syria. The aim of the study was to determine the association between indices of central obesity and to compare the associations of, waist circumference; waist-to-hip ratio or body mass index (BMI) with calorie intake. The study will also look into the association between dietary patterns, central obesity and chronic diseases i.e. number of servings of fruits, vegetables, dairy products and their relation with the chronic diseases such as diabetes, hypertension, CVD and arthritis. 


\section{Materials and Methods}

One hundred twenty eight individuals participated in prospective cohort study which carried out September 2017 and lasted for 60 days. They participants were divided into two groups.

1) Group one: consisted of 61 males.

2) Group 2: consisted of 67 females as shown in Figure 1.

The average age of the males and females participated in the study was $52.5 \pm$ 11.65 years. Males had higher age comparing with females; their average age was $54 \pm 12.42$ years whereas the average age for females was $51 \pm 10.88$ years. These data are shown in Figure 2.

All anthropometric measurements were performed by a professional technician. Individuals of both groups were weighed using scale Omron scale/fat analyzer (Model: HBF-516B). Body weights were measured to the nearest $0.1 \mathrm{~kg}$. Measurements were taken when participants were without shoes and wearing only light clothing, their height was measured to the nearest centimeter with the participants barefooted by using stadiometer (Seca 222). After that, their BMI was calculated (weight $\mathrm{kg} /(\text { Height } \mathrm{m})^{2}$ ).

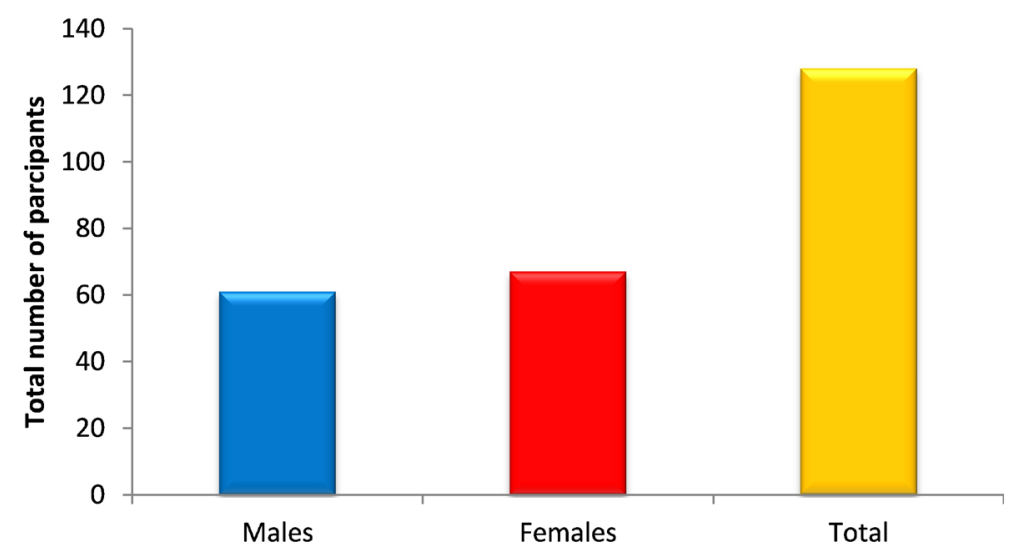

Figure 1. Number of males and females participated in the study.

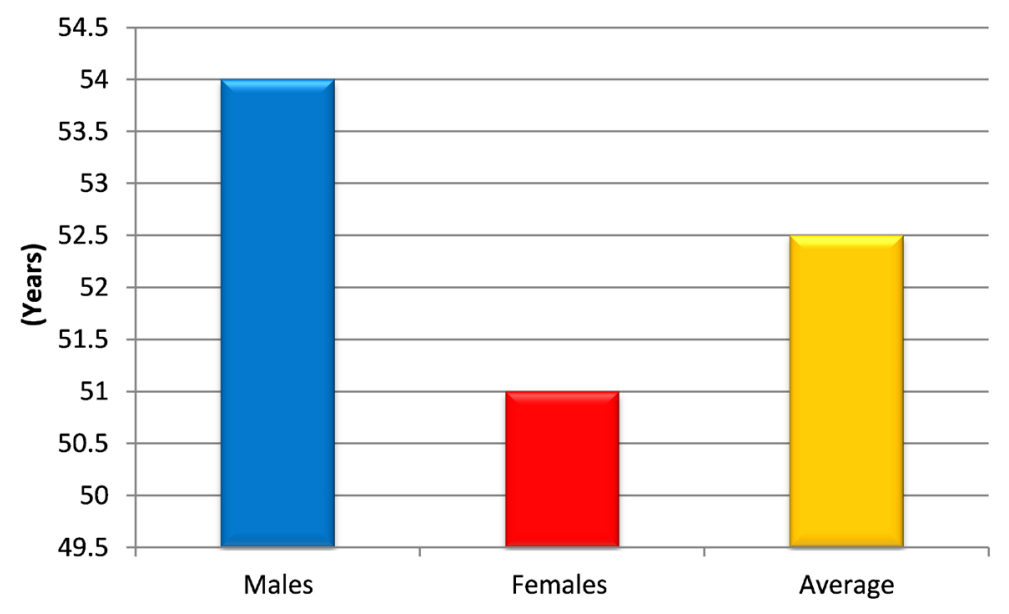

Figure 2. Average age of males and females particpnats. 
Waist and hip circumference were also measured using a regular measuring tape and then waist/hip ratio was calculated (Waist circumference $\mathrm{cm} / \mathrm{Hip}$ circumference $\mathrm{cm}$ ).

Skinfold thickness (triceps, subscapular, and prothoracic-that is, midway between the axilla and iliac crest) were measured with Harpenden's calipers and recorded to the nearest $01 \mathrm{~mm}$. The (three) skinfold thicknesses were then summed. Waist circumference was measured to the nearest centimeter at the level of the umbilicus with the subject standing and breathing normally. Hip circumference was measured to the nearest centimeter at the level of the iliac crest. Fat percentage was measured by using Omron fat analyzer (Model: HBF-516B). The waist circumference (in centimeters) was taken midway between the inferior margin of the last rib and the iliac crest in a horizontal plane. The circumferences were measured to the nearest centimeter at the end of normal expiration. Hip circumference was measured to the nearest centimeters at the level of the greater trochanters with the subjects wearing underwear or light clothing. The waist-to-hip ratio (WHR) was calculated from the values of T. H. Raimi et al. the waist and hip circumferences [8].

After 12 hours fasting, blood samples were drawn from participants of both groups by a professional nurse and were sent to the lab for analysis. The lipid profile (LDL, HDL, TG, and TC) for all participants was measured according to National Cholesterol Education Program [9].

A 24 hours recall was taken from all participants in order to figure out the number of serving size and the amount of calories consumed by each participant in each group.

A questionnaire was designed and distributed among the participants to assess their health status. The diagnosed chronic diseases were registered.

Statistical analysis was done by using SPSS software and the significance level was set at $p(0.05)$. Permission was obtained from the ethical committee in the faculty prior to the start of this study.

\section{Results}

Results have shown that average BMI for the participants was $30.5 \pm 3.93$ $\left(\mathrm{kg} / \mathrm{m}^{2}\right)$ Females had higher BMI comparing to males. There was a significant difference between males group $(28.3 \pm 4.49)$ and females group $(31.1 \pm 2.68)(p$ $<0.05)$.

With regard to waist circumference, females group had higher waist circumference $(103.1 \pm 4.83 \mathrm{~cm})$ comparing with males group $(93.9 \pm 9.04 \mathrm{~cm})$ and the difference was significant at $(p<0.05)$.

The same thing applies to hip circumference; females had higher hip circumference when compared to males. The average hip circumference was $96.3 \pm$ 14.15 and $107 \pm 4.67 \mathrm{~cm}$ for males and females groups respectively and there was a significant difference at $(p<0.05)$.

Females had also higher value of waist to hip ratio than males and the differ- 
ence was statistically significant $(p<0.05)$. Females had also higher values of skinfold thickness values $(\mathrm{mm})$ and fat percentage comparing with males and females.

The $\mathrm{W} / \mathrm{H}$ ratio was higher in females 0.98 comparing to males 0.96 and the difference was significant $(p<0.05)$. Females also had higher skin thickness when compared with males. $44.6 \pm 2.78 \mathrm{~mm}$ and $45.7 \pm 2.37$ for males and females respectively and the difference was significant $(p<0.05)$. The results are presented in Table 1 and Figures 1-6.

Females also had higher WC and HC comparing with males. The difference was statistically significant $(p<0.05)$.

With regard to WHR, males had higher values comparing to females and this is explained as males tend to have Android body shape. The difference between males and females was significant $(p<0.05)$.

The study also examined the lipid profile in males and females. Females had lower LDL values than males but they had higher values of HDL, TC and TG as shown in Table 2 and Figure 7.

Table 3 and Figure 8 show the total energy intake and the distribution of the energy among carbohydrates, protein and fat. The energy intake was almost similar in males and females ( 2800 to $2700 \mathrm{kcal}$ for males and females respectively) as shown in Table 3.

The study showed that females consumed higher percentage of calorie from CHO comparing with males (51\% to $58 \%$ ) but they had less energy intake from protein $13 \%$ to $11 \%$ and fat $36 \%$ to $31 \%$ for males and females respectively as shown in Table 3 and Figure 8.

Both groups consumed 2 servings of vegetables/day and had nil servings of dairy products. Males consumed 1 serving of fruit/day and on the contrary, females did not consume any fruits. These findings are explained in Table 4 and Figure 9.

The health status was also checked in this study. Unfortunately females had more cases of diagnosed diabetes, CVD, hypertension and arthritis comparing with males. The females had 27 cases of diabetes (represent $40.3 \%$ of total females) and males had only 20 cases of diabetes (represent $32.8 \%$ of males). Females also had 17 cases of diagnosed CVD (represent 25.4\%) comparing to 15 cases (represent 24.6\%) among males. Diagnosed hypertension cases among females were 36 cases (53.7\%) comparing to 30 cases in males or $49.2 \%$. The results are shown in Table 5 and Figure 10.

\section{Discussion}

Higher values of BMI, waist circumference, hip circumference, skinfold thickness and fat percentage are associated with high rates of diabetes, CVD, hypertension and arthritis. Similar to these findings have been published in a study by Lakka et al. which indicated that abdominal obesity is associated with increased risk of acute coronary events in men and visceral obesity can be more important 
Table 1. Anthropometric measurements of males and females groups.

\begin{tabular}{cccc}
\hline & All participants $\mathrm{n}=128$ & Males $\mathrm{n}=61$ & Females $\mathrm{n}=67$ \\
\hline $\begin{array}{c}\text { Age average } \\
\text { (Years) } \\
\text { BMI }\end{array}$ & $52.5 \pm 9.65$ & $54 \pm 10.11$ & $51 \pm 9.59$ \\
$\begin{array}{c}\text { (Weight kg/(height m) } \\
\text { Waist circumference }(\mathrm{cm})\end{array}$ & $30.5 \pm 3.93$ & $28.3 \pm 4.49$ & $31.1 \pm 2.68^{*}$ \\
Hip circumference $(\mathrm{cm})$ & $101.9 \pm 11.65$ & $96.3 \pm 14.15$ & $107 \pm 4.67^{*}$ \\
Waist/Hip ratio & 0.97 & 0.96 & $0.98^{*}$ \\
Skinfold Measurements $(\mathrm{mm})$ & $44.6 \pm 2.78$ & $44.1 \pm 3.12$ & $45.7 \pm 2.37$ \\
Fat Percentage & $35.8 \pm 8.37$ & $33.5 \pm 7.66$ & $37.6 \pm 9.78^{*}$ \\
\hline
\end{tabular}

*Significant difference $(p<0.05)$.

Table 2. Lipid profile in males and females groups.

\begin{tabular}{cccc}
\hline & All participants & Males & Females \\
\hline LDL mg/dL & $140 \pm 24.71$ & $148^{*} \pm 22.41$ & $133 \pm 19.33$ \\
HDL mg/dL & $42 \pm 10.61$ & $38 \pm 9.45$ & $44^{*} \pm 11.23$ \\
Total Cholesterol mg/dL & $273 \pm 31.21$ & $260 \pm 26.84$ & $280^{*} \pm 27.43$ \\
Triglycerides mg/dL & $161 \pm 36.76$ & $147 \pm 29.12$ & $176^{*} \pm 32.19$ \\
\hline
\end{tabular}

${ }^{*}$ Significant difference $(p<0.05)$.

Table 3. Calorie intake and calorie participation from each nutrient.

\begin{tabular}{cccc}
\hline & All participants & Males & Females \\
\hline Total calories & $2745 \pm 58.88$ & $2800 \pm 60.67$ & $2700 \pm 57.71$ \\
\% Carbohydrates & $54 \pm 10.12$ & $51 \pm 9.91$ & $58^{*} \pm 10.98$ \\
\% Protein & $12 \pm 2.63$ & $13^{*} \pm 3.11$ & $11 \pm 2.14$ \\
\% Fat & $33.5 \pm 6.43$ & $36^{\star} \pm 7.13$ & $31 \pm 5.76$ \\
\hline
\end{tabular}

${ }^{\star}$ Significant difference $(p<0.5)$.

Table 4. Number of servings from each food group.

\begin{tabular}{cccc}
\hline Number of servings & All participants & Males & Females \\
\hline Vegetable & 2 & 2 & 2 \\
Fruits & 1 & 0 & 0 \\
Dairy & 0 & 0 & 0 \\
\hline
\end{tabular}

Table 5. Number of males and females diagnosed with chronic diseases.

\begin{tabular}{cccccc}
\hline $\begin{array}{c}\text { Number of Diagnosed } \\
\text { Patients }\end{array}$ & $\begin{array}{c}\text { All } \\
\text { participants }\end{array}$ & No. Males & $\%$ & No. Females & $\%$ \\
\hline Diabetes & 47 & 20 & $32.8 \%$ & 27 & $40.3 \%$ \\
\hline
\end{tabular}




\section{Continued}

\begin{tabular}{cccccc}
\hline CVD & 32 & 15 & $24.6 \%$ & 17 & 25.4 \\
Hypertension & 66 & 30 & $49.2 \%$ & 36 & $53.7 \%$ \\
Arthritis & 61 & 28 & $45.9 \%$ & 33 & $49.3 \%$ \\
\hline
\end{tabular}

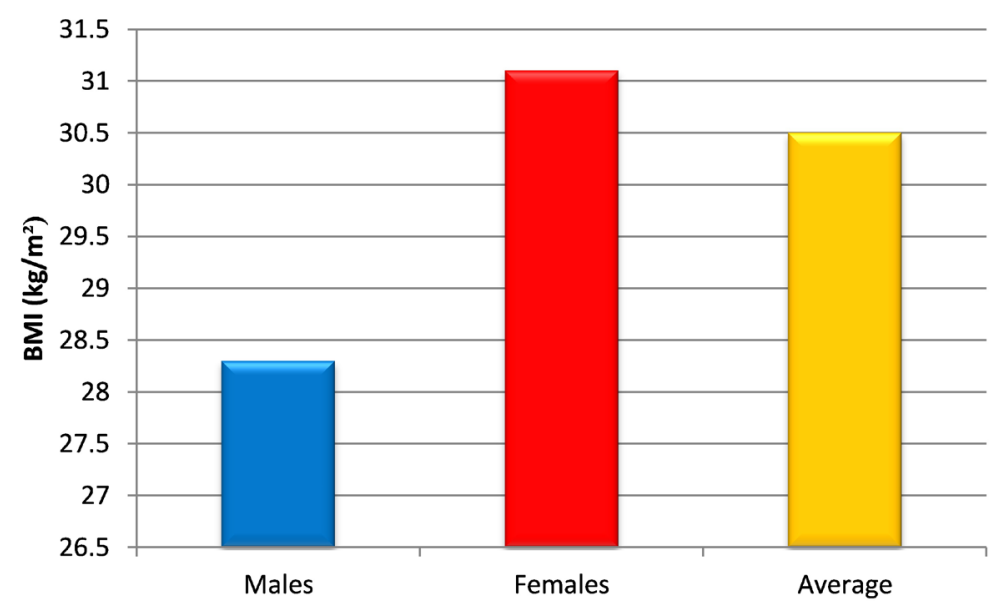

Figure 3. BMI of males and females participants.

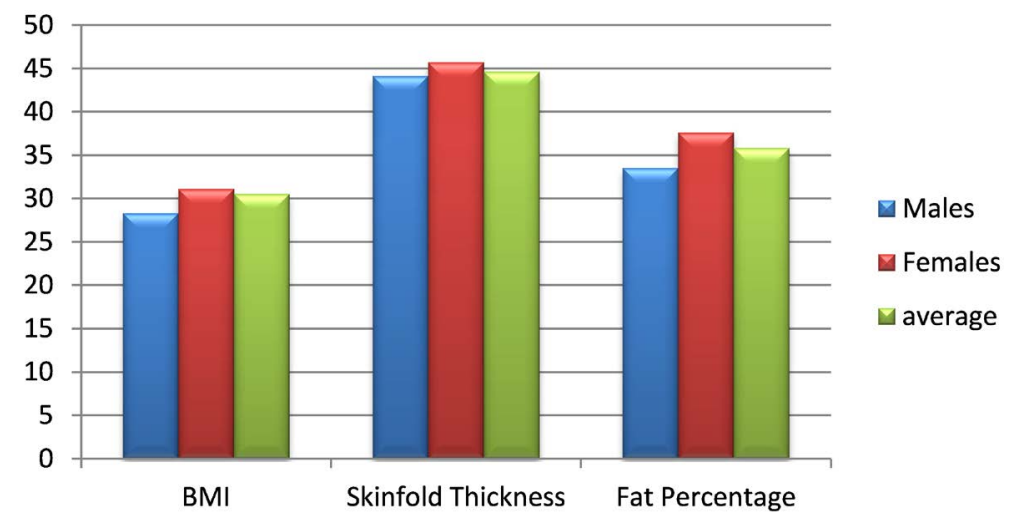

Figure 4. BMI, skinfold thickness and fat $\%$ among participants.

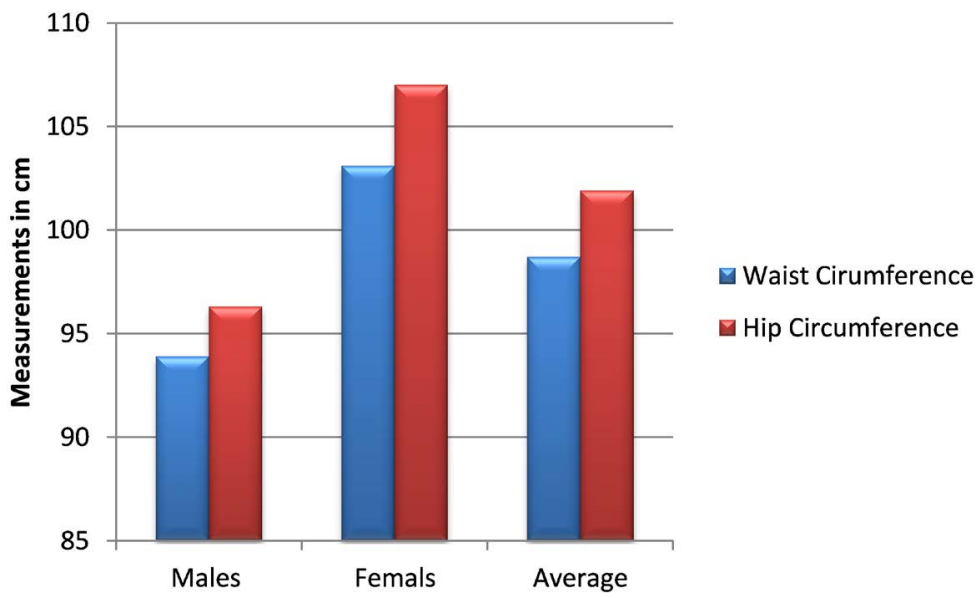

Figure 5. Waist and hip circumference of the males and females. 


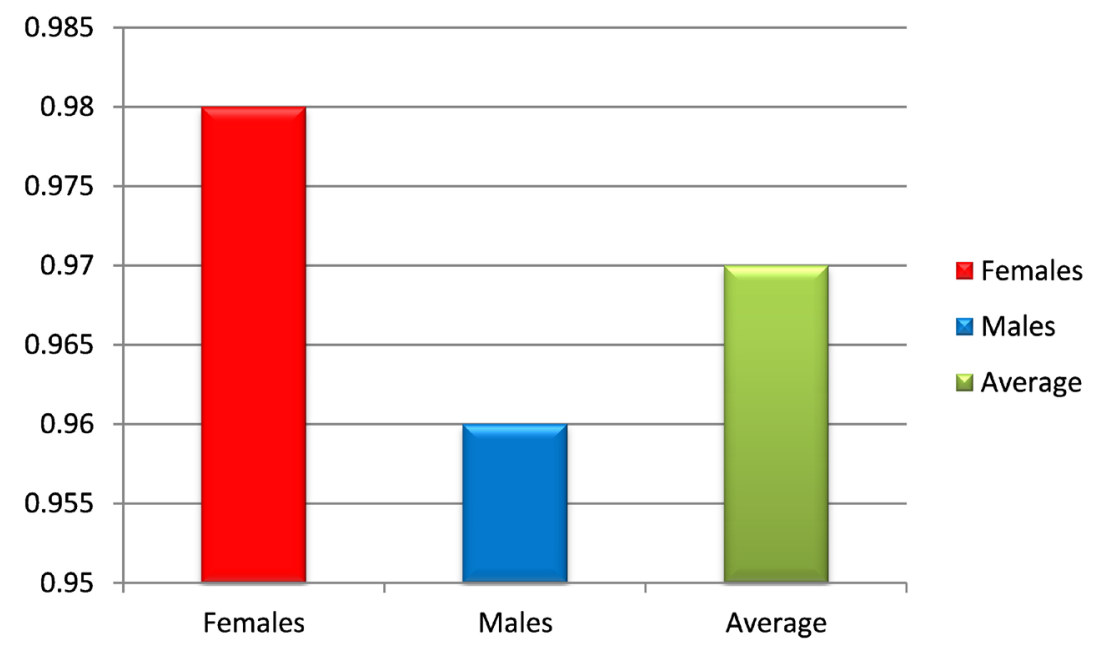

Figure 6. Waist/hip ratio in males and females.

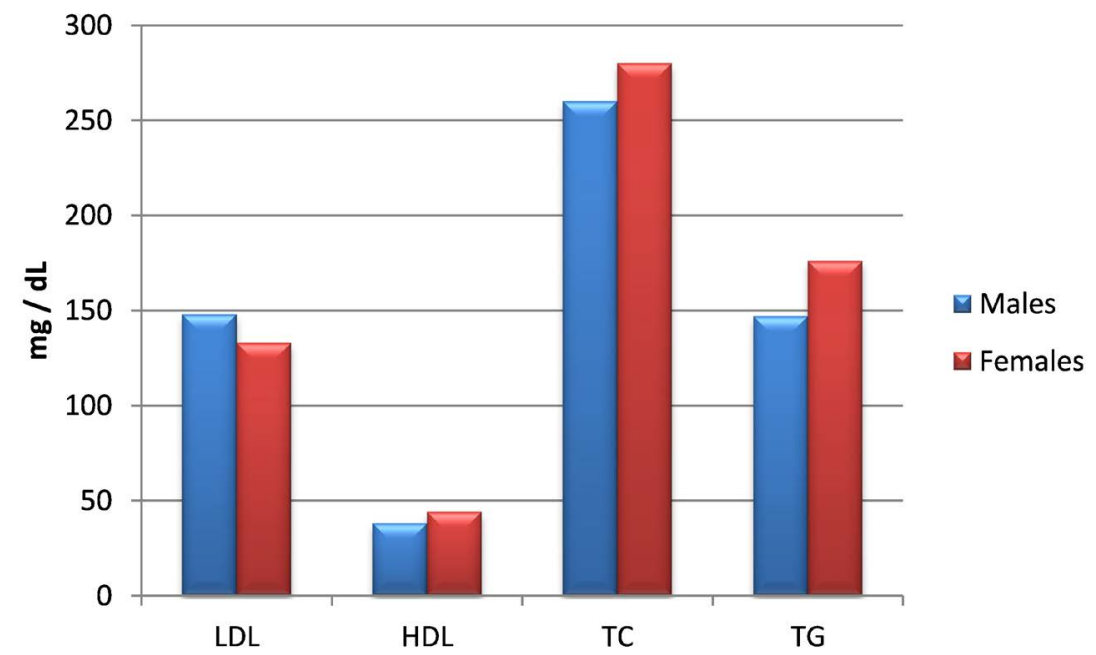

Figure 7. Lipid profile of males and females participants.

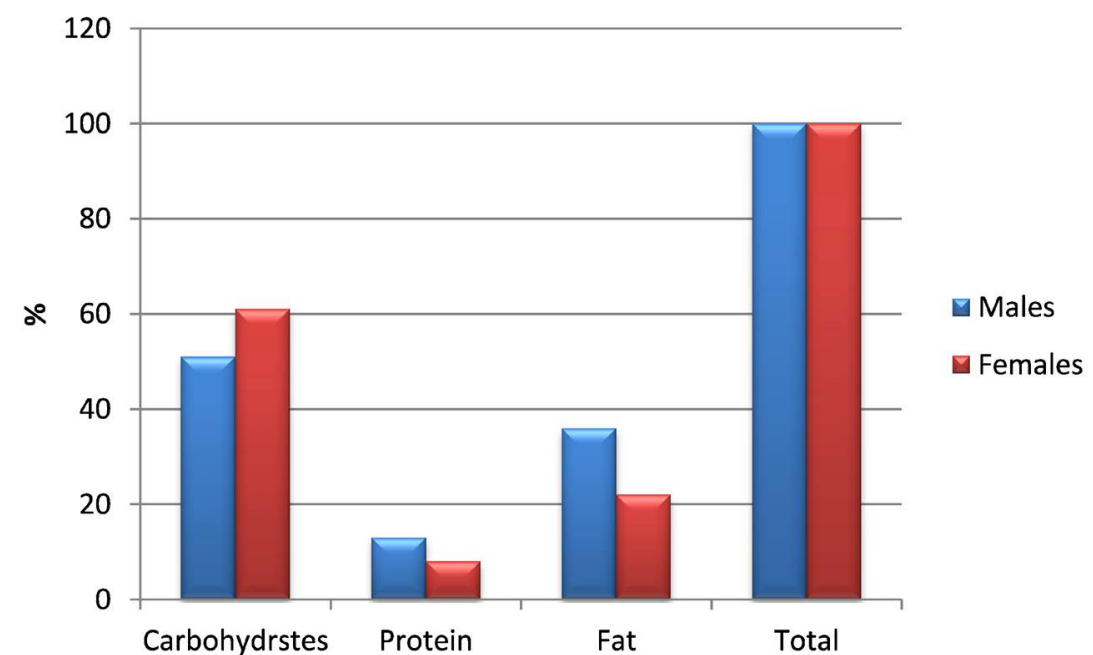

Figure 8. Percnetage of energy consumed from differnt nutrients in both group. 


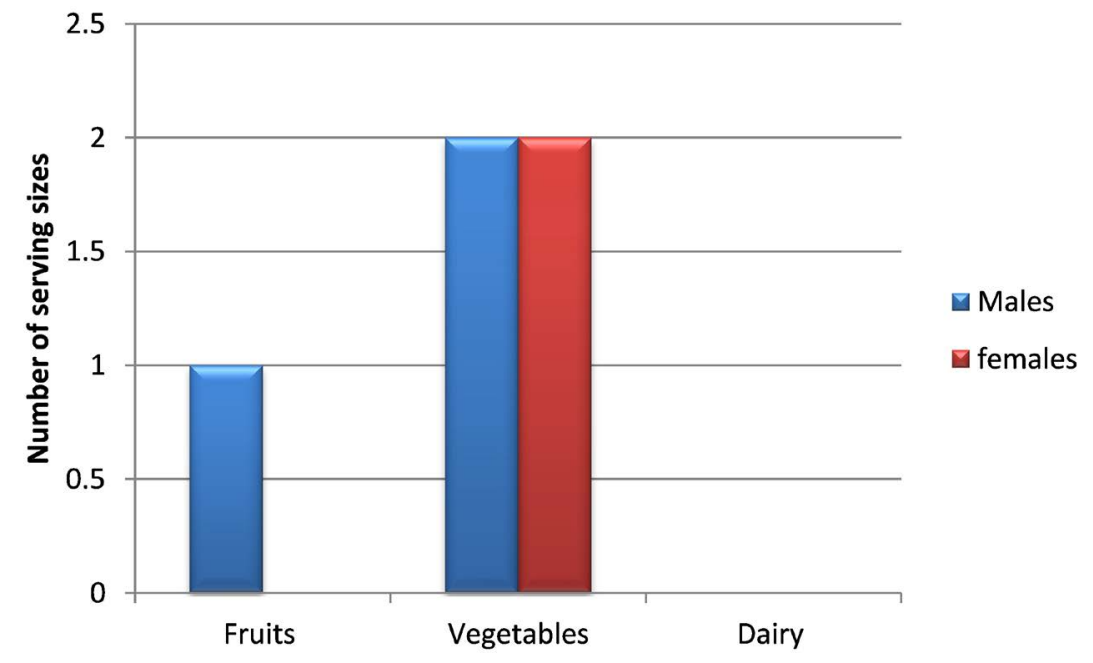

Figure 9. Fruits, vegetables and dairy consumption among participants.

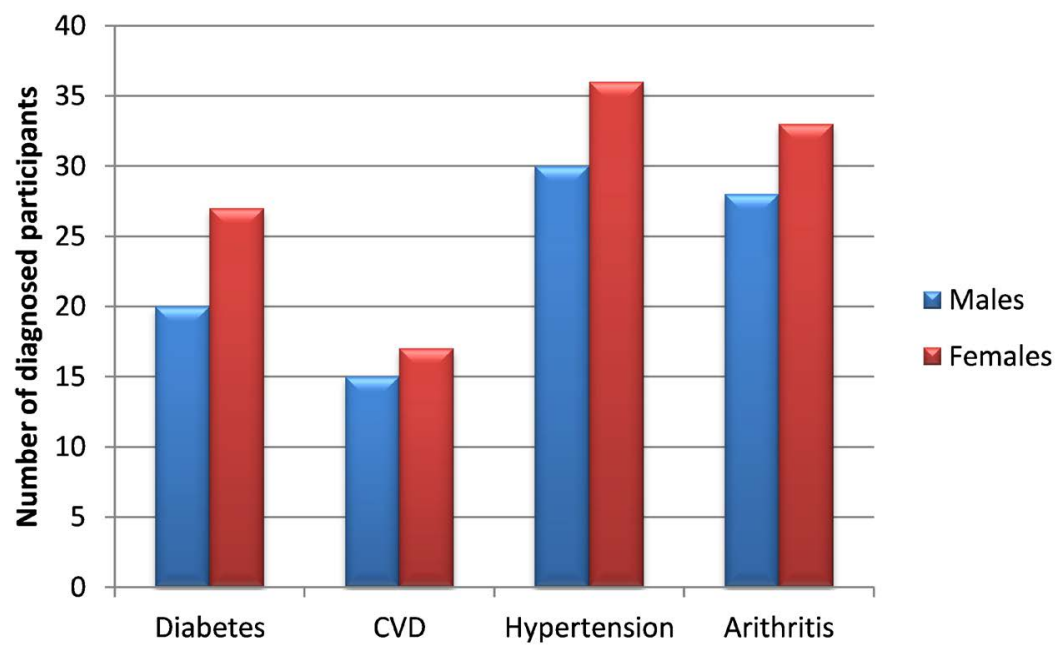

Figure 10. The prevalence of chronic diseases among participants.

than general obesity [10]. Waist circumference, waist-to-hip ratio, and BMI were positively associated with blood pressure, diabetes, low-density lipoprotein (LDL)-cholesterol, triglycerides and inversely correlated to high-density lipoprotein (HDL)-cholesterol [11]. There was an association between waist circumference, waist-to-hip ratio, BMI and chronic disease such as diabetes, CVD and hypertension [12].

This study has shown that the female participants had greater mean BMI, WC, and WHR compared with the males. This is in total agreement with other studies [13] [14]. This can be explained by explaining that men are generally more active than women. Other possible contributors to the gender difference in the obesity include age, nutritional and biological factors [15].

Consistent with previous reports [16], there was a good correlation between body mass index and the indices of central obesity. Among the female partici- 
pants, WC correlated equally with BMI but both correlated better than WHR. This observation is similar to the report by previous authors [17]. This is not unexpected since both indices are measures of adiposity. Abdominal obesity is an independent risk factor for coronary heart disease in middle-aged men and even more important than overall obesity [18].

\section{Conclusions}

Obese and overweight people have an increased risk of dying or of contracting a serious illness.

The effect of excess weight on chronic diseases and mortality has been well established. This study has been an attempt to see whether various distributions of adipose tissue might be associated with an increased risk of chronic diseases. We studied the relation between baseline measurements of abdominal adipose tissue distribution (waist to hip ratio) and commonly used indices of obesity and the incidences of diabetes, heart diseases, and hypertension.

\section{Recommendations}

Healthy lifestyle is a key for prevention of chronic disease. This can be done through weight reduction in overweigh and obese individuals by having negative energy balance through consuming more fruits and vegetables (5 servings per day) added to that increased physical activity levels. BMI lower than 25 is the main factor in prevention of chronic diseases and their complications.

\section{References}

[1] World Health Organization (2000) Obesity: Preventing and Managing the Global Epidemic. Geneva.

[2] Huang, K.C., Lin, W.Y., Lee, L.T., et al. (2002) Four Anthropometric Indices and Cardiovascular Risk Factors in Taiwan. International Journal of Obesity, 26, 1060-1068. https://doi.org/10.1038/sj.ijo.0802047

[3] Expert Panel on Detection, Evaluation, and Treatment of High Blood Cholesterol in Adults (2001) Executive Summary of the Third Report of the National Cholesterol Education Program (NCEP) Expert Panel on Detection, Evaluation, and Treatment of High Blood Cholesterol in Adults (Adult Treatment Panel III). JAMA, 285, 2486-2497. https://doi.org/10.1001/jama.285.19.2486

[4] World Health Organization (1999) Definition and Diagnosis of Diabetes Mellitus and Intermediate Hyperglycemia: Report of a WHO Consultation. Geneva.

[5] Goh, L.G., Dhaliwal, S.S., Welborn, T.A., Lee, A.H. and Della, P.R. (2014) Anthropometric Measurements of General and Central Obesity and the Prediction of Cardiovascular Disease Risk in Women: A Cross-Sectional Study. BMJ Open, 4, e004138. https://doi.org/10.1136/bmjopen-2013-004138

[6] Ashwell, M., Gunn, P. and Gibson, S. (2012) Waist-to-Height Ratio Is a Better Screening Tool than Waist Circumference and BMI for Adult Cardiometabolic Risk Factors: Systematic Review and Meta-Analysis. Obesity Reviews, 13, 275-286. https://doi.org/10.1111/j.1467-789X.2011.00952.x

[7] Page, J.H., Rexrode, K.M., Hu, F., Albert, C.M., Chae, C.U. and Manson, J.E. (2009) 
Waist-Height Ratio as a Predictor of Coronary Heart Disease among Women. Epidemiology, 20, 361-366. https://doi.org/10.1097/EDE.0b013e31819f38f1

[8] Raimi, T.H., Fasanmade, O., Odusan, O. and Ohwovoriole, A.E. (2015) The Best Central Adiposity Index in the Prediction of Cardiovascular Risk Factors in South-Western Nigeria. Open Journal of Endocrine and Metabolic Diseases, 5, 184-192. https://doi.org/10.4236/ojemd.2015.512023

[9] NIH, National Heart, Lung, and Blood Institute (1995) National Cholesterol Education Program. Recommendations on Lipoprotein Measurement: From the Working Group on Lipoprotein Measurement. NIH Publication No. 95-3044, Bethesda, 186 p.

[10] Lakka, H.-M., Lakka, T.A., Tuomilehto, J. and Salonen, J.T. (2002) Abdominal Obesity Is Associated with Increased Risk of Acute Coronary Events in Men. European Heart Journal, 23, 706-713. https://doi.org/10.1053/euhj.2001.2889

[11] Knopp, R.H., Paramsothy, P., Retzlaff, B.M., Fish, B., Walden, C., Dowdy, A., et al. (2005) Gender Differences in Lipoprotein Metabolism and Dietary Response: Basis in Hormonal Differences and Implications for Cardiovascular Disease. Current Atherosclerosis Reports, 7, 472-479. https://doi.org/10.1007/s11883-005-0065-6

[12] Farin, H.M., Abbasi, F. and Reaven, G.M. (2006) Comparison of Body Mass Index versus Waist Circumference with the Metabolic Changes That Increase the Risk of Cardiovascular Disease in Insulin-Resistant Individuals. American Journal of Cardiology, 98, 1053-1056. https://doi.org/10.1016/j.amjcard.2006.05.025

[13] Pettersson, J., Johansson, K., Rossner, S. and Neovius, M. (2008) Prevalence of Obesity and Abdominal Obesity in Swedish Primary Care and Occupational Health Clinics. Obesity Facts, 1, 251-257. https://doi.org/10.1159/000156530

[14] Liu, A., Abbasi, F. and Reaven, G. (2011) Adiposity Indices in the Prediction of Metabolic Abnormalities Associated with Cardiovascular Disease in Non-Diabetic Adults. Nutrition, Metabolism and Cardiovascular Diseases, 21, 553-560. https://doi.org/10.1016/j.numecd.2009.12.009

[15] Gruson, E., Montaye, M., Kee, F., Wagner, A., Bingham, A., Ruidavets, J.B., Haas, B., Evans, A., Ferrières, J., Ducimetière, P.P., Amouyel, P. and Dallongeville, J. (2010) Anthropometric Assessment of Abdominal Obesity and Coronary Heart Disease Risk in Men: The PRIME Study. Heart, 96, 136-140. https://doi.org/10.1136/hrt.2009.171447

[16] Flegal, K.M., Kit, B.K., Orpana, H. and Graubard, B.I. (2013) Association of All-Cause Mortality with Overweight and Obesity Using Standard Body Mass Index Categories: A Systematic Review and Meta-Analysis. JAMA, 309, 71-82. https://doi.org/10.1001/jama.2012.113905

[17] Browning, L.M., Hsieh, S.D. and Ashwell, M. (2010) A Systematic Review of Waist-to-Height Ratio as a Screening Tool for the Prediction of Cardiovascular Disease and Diabetes: 0.5 Could Be a Suitable Global Boundary Value. Nutrition Research Reviews, 23, 247-269. https://doi.org/10.1017/S0954422410000144

[18] Sung, K.C., Ryu, S. and Reaven, G.M. (2007) Relationship between Obesity and Several Cardiovascular Disease Risk Factors in Apparently Healthy Korean Individuals: Comparison of Body Mass Index and Waist Circumference. Metabolism: Clinical and Experimental, 56, 297-303. https://doi.org/10.1016/j.metabol.2006.09.016 